\title{
The Cognitive Dimension in Language Study*
}

\author{
Pieter A. M. Seuren
}

\begin{abstract}
The main argument of this paper is that language, like cognition, is basically intensional, i.e. expression of thoughts. The philosophical and logical consequences of this view are discussed and partly elaborated. The paper implies a fundamental critique of the study of language during the 20th century, which failed to recognize the essential cognitive (intensional) nature of language. A plea is made for a re-appraisal of late 19th century approaches in philosophy (e.g. Meinong, Stout), which are said to have been on the right track though lacking in formal precision. The 20th century extensional view of logic and language, which goes back to the early $1900 \mathrm{~s}$, is subjected to a fundamental critique. The intensional nature of language is shown to have far-reaching consequences for the theory of grammar and meaning. The formal grammatical and semantic theories developed during the 20th century from an extensional point of view are best seen as a prelude to more adequate intensional formal theories.
\end{abstract}

\section{Introduction}

This paper is a result of my long-standing conviction that during the twentieth century theoretical linguistics has suffered from one overarching defect, the neglect of cognition as a constitutive element in the make-up of natural language. There have, of course, been many positive developments as well. As a subject, linguistics has taken an enormous flight, resulting in vastly superior knowledge of the languages of the world, their common features and their differences. Our observational powers in the areas of syntax, morphology, phonology and phonetics have been considerably sharpened. Our insights into the nature of dialectal and sociolectal variation have been extended and deepened, and more real progress could be mentioned. On the formal front, the last century has witnessed dramatically improved mathematical insights into the nature of formal languages and, helped by developments in logic, corresponding dramatic improvements of the formal means of analysis and description of complex structures of symbols and their model-theoretic properties. All that has been, and is, of great service. Yet something serious has been lacking, and that, I think, is a formal and philosophical account of the dependency of natural language on cognition. 
Exactly one hundred years ago, insights were coming to fruition regarding the projective powers of the human mind in dealing with the world and getting to know about it (e.g. Meinong 1904), and, at the same time, the cognitively dynamic nature of human language (e.g. Stout 1896). But hardly any satisfactory progress has been made, in the meantime, regarding the formal analysis and description of the cognitive or intensional processes involved. In principle, the technical notions that were developed in logic and mathematics during the twentieth century were limited to systems that were in principle extensional, leaving the projective powers of cognition unaccounted for.

Given both the possibilities and the limitations of such extensional systems, the tendency was to maximize their use and cut the object of enquiry down to their size. Language, in other words, was tied to the Procrustean bed of the formal systems available and maimed in the process. Those who did not want to take part in this disfiguring formal treatment inevitably found themselves relegated to a less respected limbo of vagueness and imprecision. In the case of pragmatics, imprecise and intuition-based analyses were used to rescue language from being crippled too badly by the imposition of an inadequate logical and model-theoretic system. It is my feeling that what is wanted in the present situation is a bridge between, on the one hand, the kind of formal treatment we have, for good reasons, grown used to and the still largely unexplored domains of mind and thought, on the other.

The overall landscape of linguistic interaction as it will be sketched in the following pages is still full of unmapped areas, like our planet a few centuries ago. It seems premature and unwise, therefore, to jump to formalizations, even if some among our colleagues, especially those with a training in formal logic, feel that only fully formalized theories can make a contribution to science. These logicians or logically minded linguists are wrong, and their unwise attitude explains a great deal of the theoretical myopia we have unfortunately had to witness during the last century. Formalization is the last step in a long process of finding one's feet and getting one's bearings, of cautious exploration and ground testing, of becoming familiar with the object of enquiry and discovering possible generalizations and causal connections. Those who insist on full formalization straight away show that they have little idea of what real science amounts to.

On the other hand, however, those who reject any attempt at formalization are equally unwise. One of the important lessons of the past century has been that marshalling one's findings into a formal system, either as a data survey or as a formal theory with predictive power, is the indispensable cap on all serious research. The mathematical turn of the last century has led to such improvements in the clarity and systematicity of thinking in the traditional human sciences that it can no longer be rejected with impunity. A sensible middle course should, 
therefore, be followed. On the one hand, the available facts should be scrutinized as completely and as impartially as is feasible given the circumstances. On the other hand, the results should, at the right moment, be cast into the format of a formal survey or theory, whereby the formal sciences of logic and mathematics should be called in for help as much and as quickly as possible.

\section{The semiotic architecture}

Let us start with the famous semiotic triangle in Ogden \& Richards (1923:11), shown in fig. 1. Their book, The Meaning of Meaning, of 1923, is a curious but also very inspiring struggle between the forces of the 19th and those of the 20th century. On the one hand, the authors have not yet taken leave of the notion of thought, a notion that was of prime importance in the study of language and logic during the 19th century. On the other hand, they wrestle with the then modern developments of pragmatism, neopositivism and even behaviourism. Despite the confusions, uncertainties and other great inadequacies, largely due to the limited technical and formal means at their disposal, their triangle of semiotic relations was a masterful synthesis of their thoughts on the subject, a synthesis that should have inspired the 20th century philosophers of language much more than it did.

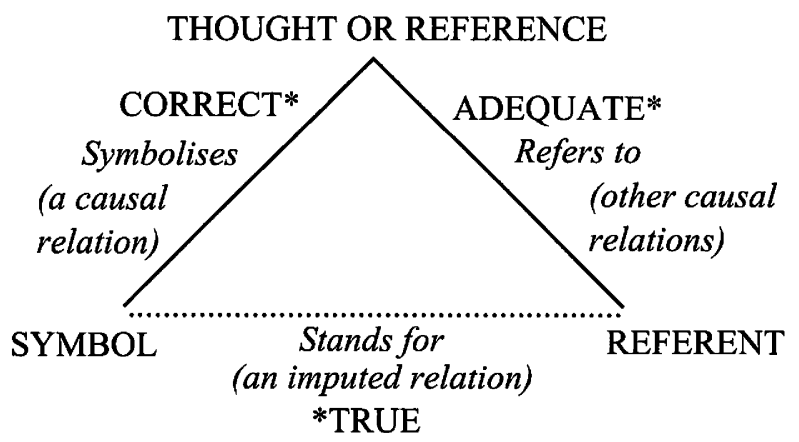

Figure 1: Ogden \& Richards's semiotic triangle

To adapt the terminology to the present day, we read 'linguistic utterance' where Ogden \& Richards read 'symbol'. Where they read 'thought or reference' we read simply 'thought' or, if you like, 'mind', and for their 'referent' we read 'world'.

We then see that the authors see a causal relation of 'symbolisation' between utterance and thought: the former is a rule-governed expression of the latter, while the latter is a reconstruction guided by the former, both processes being subject to causal mechanisms within the speaker's body, mind and all. This much is easily understood and subscribed to by modern linguists (to the extent that they subscribe to a realist interpretation of their theories). 
We also notice that Ogden \& Richards establish another causal relation or set of relations between the mind and the world, in an attempt to account for the relation between thoughts and what they are about. We speak here of an intentional relation, that is, the relation between, on the one hand, mental representations and whatever linguistic or artistic structures that go proxy for them, and, on the other, those aspects in the real or any imagined world that the representations are meant to be about. Intentionality, in short, is the representational character, the 'aboutness', of thoughts and their symbolizations.

This intentional relation we find much more problematic. In fact, hardly anything substantial has been said during the 20th century about the intentionality of thought and language, that is, about the fact that the use of language is intended to be about things in the or a world. This, of course, must be a central issue in any theory of meaning and I shall argue that the standard answers provided by modern semantic theory are, though of consummate formal and technical prowess, badly lacking in adequacy.

This point is directly connected with the third line in Ogden \& Richards's triangle, the base line. This is not a solid but a dotted line, signalling the fact that it does not express a causal but, as the authors say, an 'imputed' relation. We take the authors to mean by this that in describing the relation between linguistic utterances and the world we behave as if this were a direct causal relation, even if we know that this is not so.

This, now, is a profoundly misleading perspective which has, in my view, been one of the main sources of error not only in modern semantics and philosophy of language, but also in the very conceptual frame determining the ordinary linguist's view of language. Both the origins and the consequences of this misleading perspective go deep and are not always directly visible, but they are all-pervasive and therefore of the greatest importance for the overall direction of research and the interpretation of its results. In incorporating the dotted base line into their triangle, Ogden \& Richards tried to reconcile the irreconcilable. The proper scientific perspective, as I see it, is expressed more adequately by an emendation of Ogden and Richards's triangle as shown in fig. 2.

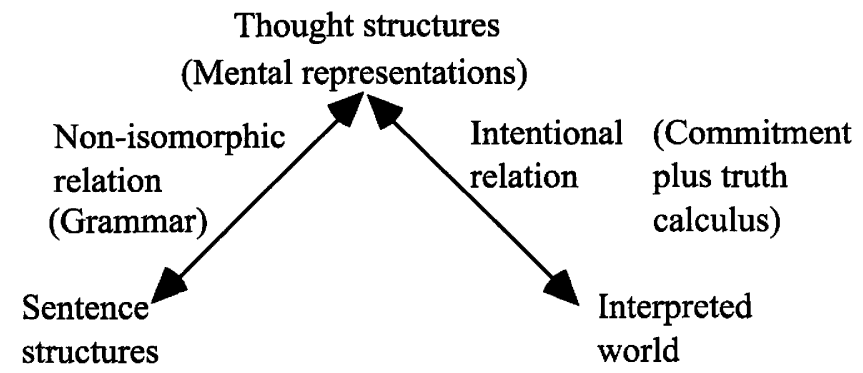

Figure 2: The causal relationships of language, mind and world 
In this view, there is a non-isomorphic relation between sentence structures and thought structures (the latter to be reconstructed by hypothesis on the basis of semantic and grammatical phenomena together with situational and world knowledge). In principle, the grammar of each language maps actual thought structures onto sentence structures and vice versa. Then, thought structures (mental representations) not only have a truth value with regard to what they are about in the world, but, equally essentially, embody a socially binding commitment on the part of the speaker/writer with regard to the proposition contained in the thought and expressed in the uttered sentence.

When we speak of the interpretation of an uttered sentence, we speak of its property of revealing to a comprehending listener/reader with close to full certainty what thought, corresponding with the uttered sentence, has occurred in the speaker/writer's mind. That thought has at least two main aspects. It contains a commitment on the part of the speaker/writer with regard to a proposition. We take 'proposition' here in an old-fashioned, even Aristotelian, sense: a proposition consists of the mental assignment of a property to one or more (real or imagined) entities. Such a mental assignment is either true or false: propositions are the primary bearers of truth values. On the other hand, the commitment specifies the kind of social responsibility the speaker/writer has decided to take on with respect to the proposition at hand by uttering the thought. Fig. 3 shows this more detailed architecture of the semiotic environment of human language. ${ }^{1}$

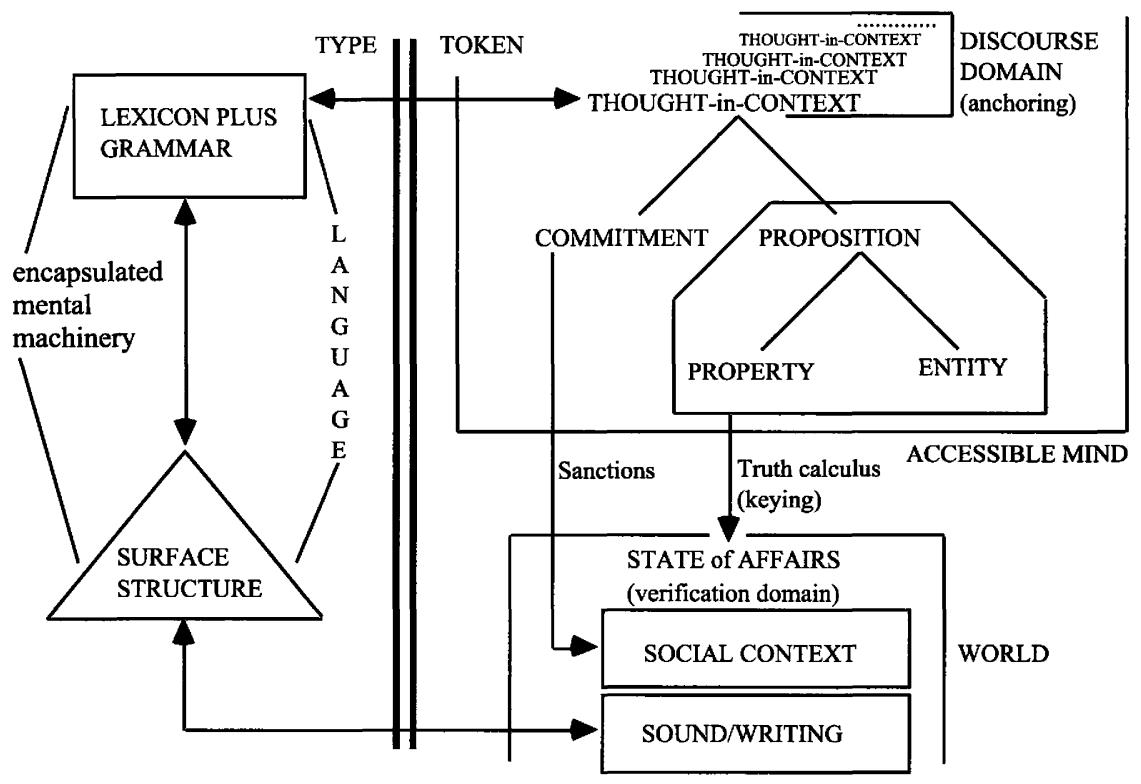

Figure 3: A more elaborate semiotic architecture 
Clearly, what is contained in fig. 3 constitutes an enormous research programme. Unfortunately, one has to say that most of this programme is still to be carried out, and that most of what has been achieved in the 20th century, though extremely useful in a formal or technical sense, is misguided in that it seeks to elaborate a non-existent ('imputed') direct relation between surface structure and whatever is the case in the or a world. In the following section we will investigate some of the historical roots of this unhappy state of affairs.

\section{Logical semantics: the Principle of Extensionality}

During the twentieth century, the human sciences have been characterized by a drive for scientific and formal precision, together with a fear for mental phenomena, in that order. This is precisely what we find not only in linguistics but also, and in a more pronounced form, in the 20th century developments in logic and semantics.

As far as I have been able to ascertain, the crucial mathematical turn in logic and semantics happened in the early years of the last century, although there had been half a century of preparatory developments. Around the year 1903 Russell, one of the fathers of modern logic, was struggling with his ontology. He tried, but failed, to understand his contemporaries Gottlob Frege and Alexius Meinong (as he failed to understand Aristotle's ontology). Yet he wrote repeatedly about Meinong, first praising (1903[37]), later attacking him (1905a, 1905b), in either case, however, without understanding him properly. By 1905 he had attained greater clarity in his thoughts about ontology (although his criterion of extensionality lacked clarity; as is shown in 6.2 below), and had opted for a strictly extensional universe, that is (in our terms), a universe consisting exclusively of entities that play their part in a system of physical causes and effects. He banned from his ontology all intensional entities, i.e. entities that are conjured up by human imagination, such as Sherlock Holmes or the Abominable Snowman, or mermaids and unicorns (see 6.2 below for further comment). But in 1903, when he published his Principles of Mathematics, there was still considerable confusion. ${ }^{2}$ Two passages in this book show the struggle, and the incompatibility, of Russell's thoughts on the subject. Early on in the book, on p. 33, he declares his antipsychologism in logic in the following terms:

In the discussion of inference, it is common to permit the intrusion of a psychological element, and to consider our acquisition of new knowledge by its means. But it is plain that where we validly infer one proposition from another, we do so in virtue of a relation which holds between the two propositions whether we perceive it or not: the mind, in fact, is as purely receptive in inference as common sense supposes it to be in perception of sensible objects. The relation in virtue of which it is possible for us validly to infer is what I call material implication. (italics mine)

(Russell 1903[37]:33) 
One notes first that Russell assigns some sort of independent status to propositions, as if a proposition could be there independently of the human. being conceiving it-a notion worked out in greater detail, but still lacking in force, in Frege (1918). Then, more importantly, one sees that the mind is said to be no more than a passive transfer passage between the world and the logical language. Russell is, however, apparently unaware that this rejection of the 'psychological element' in logical deduction is incompatible with an ontology that assigns being, but not existence, to intensional entities, that is, to objects of thought. On p. 449 of the same book he writes, inspired by Meinong:

\footnotetext{
Being is that which belongs to every conceivable term, to every possible object of thought-in short to everything that can possibly occur in any proposition, true or false, and to all such propositions themselves. ... "A is not" must always be either false or meaningless. For if A were nothing, it could not be said not to be. ... Numbers, the Homeric gods, relations, chimeras and four-dimensional spaces all have being, for if they were not entities of a kind, we could make no propositions about them. Thus being is a general attribute of everything, and to mention anything, is to show that it is. ... Existence, on the contrary, is the prerogative of some only amongst beings. To exist is to have a specific relation to existence-a relation, by the way, which existence itself does not have. (Russell 1903[37]:449)
}

There is a hidden conflict between these two passages. A logic without psychology can only be based on a notion of truth that is restricted to properties of really existing entities and cannot take into account anything as intangible and shadowy as 'things' that do not exist but owe their being to their having merely been thought up or imagined. Such a logic works well for mathematics, as the elements occurring in mathematical structures are never themselves equipped with powers of imagination (though the mathematician himself clearly is), and also for those applications where only really existing entities are at issue.

The kind of logic Russell was after was of the mathematical kind, mainly because his primary concern was the foundations of mathematics, and not the semantics of natural language, which, for him, was no more than a testing ground enlivened by handicaps that might occasionally be interesting. ${ }^{3}$ The logic Russell envisaged is based on the axiom of identity (every entity is identical to itself and different from any other entity), and the axiom of consistency (no state of affairs can both be the case and not be the case at the same time). It moreover restricts itself to an ontology where only really existing entities, with their proper identity, have a place. ${ }^{4}$ Logical systems that exclude thought-up entities and stay within the axioms of identity and consistency are subject to the Principle of Extensionality. The worlds to which they are applicable are extensional worlds.

'Objects of thought' cannot play a role in an extensional logic since thoughtup objects and worlds are not per se subject to the axioms of identity and consistency that hold for the world of existing entities. Thoughts and thought- 
up objects often stray beyond the constraints of identity and consistency that characterize extensional logical systems, and they do so to different degrees. Dreams, for example, tend to violate the Principle of Extensionality more drastically than scientific hypotheses. Such phenomena have to be accounted for: to the extent that dreams or scientific hypotheses are expressible in language, they must have their semantics. To impose the Principle of Extensionality upon thoughts and objects of thought is to mutilate the object of enquiry. For Russell, however, the inclusion of thoughts and thought-up objects meant a mutilation of his object of enquiry.

By 1905 Russell had discovered the incompatibility between his logical ideals and his ontology, and had made his choice. In his (1905a) he clearly opts for the non-psychological concept of logic, rejecting the distinction between being and existence. From now on, his logic is strictly extensional: there is no place for intensional, merely thought-up entities such as Atlantis or Pegasus. Existence and being are equated: if I talk about Pegasus there is nothing I talk about; therefore I talk about nothing. The alternative view, namely that in talking about Pegasus I talk about something that does not exist, and thus talk about something, though still defended in Russell (1903), is dismissed two years later. Since then, intensional entities have been in general disrepute, boosted by Quine's rhetorical blast (1953:1-19) against them.

Russell's change of mind between 1903 and 1905 is particularly evident in his attitude towards the philosophy of Alexius Meinong. Whereas, in his Principles of Mathematics of 1903, Russell is full of appreciation for Meinong, whom he quotes frequently and with approval, his review (1905b) is decidedly negative, and his famous (1905a) even dismissive. However, Russell's criticisms in (1905a) and (1905b) are largely based on terminological equivocations, as he misunderstands and confuses Meinong's distinction between 'being' (bestehen), 'existing' (existieren) and 'subsisting' (subsistieren), and implicitly restricts what he calls 'things' to 'existing things' (1905a:485), whereas in a more Meinongian universe 'things' include 'non-existing things' as well. ${ }^{5}$

\section{Possible world semantics}

Be that as it may, the strictly extensional view of logic has prevailed during the whole of the 20th century and has also placed a decisive stamp on formal theories of meaning in natural language. During the 1960s logic began to be applied to the semantics of natural language. This development is known as model-theoretic or possible world semantics. It was directly based on the work of the American logician Richard Montague ${ }^{6}$ and was an offshoot of the 'semantic movement' in logic, where model-theory was developed from the 1930s on as a new method of testing logical systems and proving theorems. 
Realizing that reference to intensional entities is an integral part of natural language, Montague developed a system of 'possible worlds' or PWs, each PW being an alternative to the actual or real world in which we live. He generalized extensional logic to all possible worlds, so that each PW can be treated by an extensional logic for it. This is called the programme of extensionalization of intensions. In each PW a term $t$ of a language $L$ has as its extension either an entity or set of entities, or $t$ lacks a value; a predicate $P$ of $L$ has a set (possibly the null set) of term extensions as its extension; a sentence $S$ of $L$ has a truth value (' 1 ' for 'true', or ' 0 ' for 'false') as its extension. Intensions are then defined as functions from PWs to extensions. Thus, the intension of a term $t$ of $\boldsymbol{L}$ is a function from all PWs to the extension of $t$ in each PW. Likewise for predicates and sentences: the intension of a predicate $P$ of $\boldsymbol{L}$ is a function from all PWs to the extension of $P$ in each PW, and the intension of a sentence $S$ of $\boldsymbol{L}$ is a function from all PWs to the extension (truth value) of $S$ in each PW, i.e. a characteristic function defining a set of PWs. The intension of a sentence $S$ is thus the set of PWs in which $S$ is true, also called, in model-theoretic terms, the proposition $S$. (Clearly, our notion of proposition is totally different.)

As was pointed out, however, by Dowty et al. (1981:170-175), this leads to serious problems that may well prove insurmountable for this entire approach. Verbs like believe, hope, realize are intensional with respect to their embedded object-clause. In the standard model-theoretic account this means that the extension of their embedded object-clause (the that-clause) is the intension of that clause when it is used as an independent sentence. Thus, a sentence like:

(1) John believes that Bert lives in Kentucky.

should be true just in case the person called 'John' is an element in the set $Y$ of those who believe that Bert lives in Kentucky. $Y$ contains precisely those entities who hold that the actual world is an element of the set of PWs (proposition) in which the sentence Bert lives in Kentucky is true. Sentence (1) thus expresses a belief-relation between the person called 'John' and the set of PWs in which Bert lives in Kentucky is true.

The problem is that, in this account, all necessarily true sentences have the same intension, namely the universe of all PWs, and all necessarily false sentences likewise, namely the null set or $\emptyset$. This means that the truth conditions for a sentence where John, or anyone, is said to believe a necessary truth, or a necessary falsehood, are identical, with the result that sentences like (2a) and $(2 b)$, or (3a) and (3b) should be synonymous, as $(2 a, b)$ both express a beliefrelation between John and the universe of all PWs, whereas $(3 a, b)$ both express a belief-relation between John and the null set:

(2) a. John believes that all bachelors are unmarried.

b. John believes that all circles are round. 
(3) a. John believes that all bachelors are married.

b. John believes that all circles are square.

Yet, as is universally acknowledged, our John may well believe (2a) but disbelieve (2b), and likewise for (3a) and (3b). Dowty et al. comment:

We must acknowledge that the problem of propositional attitude sentences is a fundamental one for possible world semantics, and for all we know, could eventually turn out to be a reason for rejecting or drastically modifying the whole possible worlds framework. (Dowty et al. 1981:175)

The situation has not changed since the publication of Dowty et al. (1981): the problem at hand has remained unsolved in model-theoretic semantics.

A similar problem occurs with reference to impossible intensional entities, such as the living dead man in a ghost story, or the round square cupola referred to by the fictitious Wyman in Quine's essay 'On what there is' (Quine 1953:45). Since, by definition, such impossible intensional entities cannot occur in any possible world, talk about the one would be the same as talk about the other, both having identical intensions. But in language this is not so and the respective expressions are not substitutable salva veritate.

It is no coincidence that PW semantics founders on impossible intensional entities and either necessary or impossible states of affairs: the products of human imagination transcend the Principle of Extensionality, with its axioms of identity and of consistency and its reduction of qualities to sets, yet they can still be expressed in natural language.

Similar problems occur with quantification over intensional entities under intensional predicates (i.e. predicates that do not require real existence of the argument term referent to produce truth), as in (4a-d):

(4) a. All goblins are imaginary.

b. Some gods are worshipped there.

c. John talked about some mermaids.

d. John talked about some square circles.

(4b), for example, may well be true without it being necessary to conclude that there are really existing gods. The reason is that an intensional predicate like $b e$ worshipped can produce truth even if the entity or set of entities to which it applies does not actually exist.

Restrictions of time and space forbid a further discussion of these complications (but see Seuren (in preparation) for further comment and a solution in terms of a theory of intensional quantification). All we can say here is that humans, with their powers of imagination, apparently create 'worlds' that defy the Principle of Extensionality, and that it is apparently possible to speak about the entities that populate such worlds. That being so, we must conclude that there is little hope for the programme of extensionalization of intensions. 
There are other problems as well. For example, model-theoretic semantics has great difficulty in dealing with cases like:

(5) John thinks that there is a thief in the attic, and he hopes that the thief is unarmed.

where the thief John hopes is unarmed must be the same individual as the thief he thinks is in the attic, even if, in reality, there may be no thief at all. ${ }^{7}$

Lexical semantics is likewise highly problematic in the model-theoretic framework, lexical meaning being drenched with cognitive elements like viewpoint, prototypicality, function, emotional attitude, etc. One single example will suffice, though many could easily be supplied. The English word threshold and the German word Schwelle have near enough identical extensions in this or any other possible world. Yet they must differ semantically: whereas Schwelle is naturally used in the word Verkehrsschwelle to denote a speed-bump, threshold is totally unfit for such a use, owing, it seems, to a deeply buried difference in functional viewpoint between the two words.

It is not possible to review the entire field of modern formal semantics in the present context. The issues involved are of too great a magnitude and complexity. But there is sufficient reason to give a hearing to those who say that the incursions of logic into linguistics, much as they have contributed to a clearer understanding of the formal and logical aspects involved, have not assigned to the human cognitive factor its rightful place in the study of language and have impoverished the philosophical insights about language and cognition that were coming to fruition around 1900. On the whole, it seems that one must conclude that even the most advanced forms of model-theoretic semantics, no matter how ingeniously devised, still fail to account satisfactorily for the truth or falsity of sentences involving predicates that are intensional with respect to one or more of their terms, like imaginary, worship, talk about, look for, etc. The fault lies with the principles. Whatever account is presented in model-theoretic terms is, in the end, both empirically inadequate and failing in generality.

\section{Eternal sentences: absence of discourse restrictions}

The Principle of Extensionality, with its banning order on psychology, has had another unfortunate consequence. Most sentences in natural languages are socalled occasion sentences (the term is Quine's). This means that when they are presented as such, written on the blackboard so to speak, it makes no sense to ask whether they are true or false. A sentence like:

(6) The girl was right after all.

is, of course, a good sentence of English, with its grammatical structure and its meaning. But it has no interpretation (in the sense defined in section 2 above) 
and it has no truth value. It will have a truth value once it has been established between speaker and listener which girl is intended, what the issue was and at what time the girl had expressed an opinion on that issue. This means that the interpretation of such a sentence is context-dependent, and context-dependency implies an appeal to cognition well beyond the linguistic information contained in the sentence itself.

Not all sentences, however, are occasion sentences. Some are so-called eternal sentences (again Quine's terminology). These are such that they need no appeal to context or discourse to have their truth value established. In general, eternal sentences contain no definite descriptions like the girl: all nominal expressions are quantified. Moreover, they are either in a generic tense, like (7a), or the tense operator is itself quantified (e.g. 'once upon a time', 'always'), as in (7c), or deictically linked with the time of speaking, as in (7b). Thus the following are examples of eternal sentences:

(7) a. All humans are mortal.

b. Some Englishmen have a bank account.

c. Once upon a time there was a big bang.

Here it makes perfect sense to ask if these sentences are true or false.

Reference through definite descriptions requires the help of cognition. Suppose John and Harry agree to meet in the pub at five. There are scores of pubs in the neighbourhood, most of them well-known to both John and Harry. Yet they know exactly in which pub to meet, that being their usual haunt. Without that knowledge, they would not know where to meet and the appointment would come to nothing. This is a general fact about definite determiners like the. The definite description the pub consists of the definite determiner the and the predicate $p u b$. Predicates have sets of term extensions as their extension, as we have just seen. That being so, the question that presents itself in a modeltheoretic set-up, is how, without any input from outside, the succeeds in singling out one specific member of the set of all pubs for the purpose of reference. The answer is that it cannot, unless the set of all pubs contains just one member. But it may contain many members, as we have seen. In other words, modeltheory is in principle unable to account for definite reference.

Russell saw this early on in the piece (just as Aristotle had intuited it, for which reason he kept definite terms outside his predicate calculus). Russell's famous article (1905a) is the first attempt in the literature to account for definite reference in terms of quantification. The hackneyed sentence:

(8) The present king of France is bald.

served as Russell's stock example. He analysed it as saying 'there is at least one $x$ such that $x$ is now king of France and $x$ is bald and such that for all $y$, if $y$ is now king of France, then $y$ is identical with $x^{\prime}$. Or, in more formulaic terms: 


$$
\exists \mathrm{x}[\operatorname{now}[\mathrm{KF}(\mathrm{x})] \wedge \mathrm{B}(\mathrm{x}) \wedge \forall \mathrm{y}[\operatorname{now}[\mathrm{KF}(\mathrm{y})] \rightarrow \mathrm{y}=\mathrm{x}]]
$$

(where 'KF' stands for 'king of France' and ' $B$ ' for 'bald'). Russell presented this analysis in the first place as a reply to Meinong, that is, as an attempt to get rid of reference to non-existing entities like the present king of France (who did not exist then and does not exist now). But its significance was greatly enhanced when Quine, in his (1960), put out his banning order on all occasion sentences and declared his programme of the elimination of particulars.

We now see clearly what motivated this programme: logic should stand as a monument of metaphysical necessity, unblemished by psychological influences. Propositions, the primary units of logic, are taken to lead their own existence, independent of any thought processes. What follows logically, follows logically, without any outside (least of all psychological) help-in fact, more or less what Russell wrote in the first passage of his (1903) quoted in section 3 above. In this view, the chances of natural language being logically sound are considered slim, though the logicians will do their best to salvage as much of it as they can.

Against this we posit that propositions, still the primary units of logic, are mental occurrences of thought. What follows logically, follows formally, i.e. in terms of the formal truth calculus alone, without any outside (least of all psychological) help, and there is no a priori reason why occurrences of thought should or could not be subjected to a formal analysis. The results of that analysis will show to what extent the semantics of natural language can be fitted into one single formal logical system (i.e. to what extent the semantics of natural language is compositional), and to what extent it has to rely on a variety of, possibly large and so far computationally intractable, formal cognitive systems mutually connected and interacting with each other. ${ }^{8}$ A dependency of language on large and so far computationally intractable cognitive systems does not mean that language is 'logically unsound', since there is the realistic possibility that its logic transcends the all too restricted limits of established extensional logico-mathematical systems. We have here before us a large field of new and exciting research, the field of cognitive modelling.

\section{Critique: a programme of intensional discourse semantics}

We think that natural language is intricately bound up with cognition, and for good functional reasons. There is no earthly reason why the interchange of messages among humans should be subject to the lofty standards of metaphysical necessity. The matter is much more mundane. Humans will do with the minimum necessary. What is already mutually known or understood need not be expressed. Instead of speaking in eternal sentences cast in bronze or hewn in marble, humans cleverly use the resources provided by context and preceding 
discourse, knowing full well that utterances tend to lead extremely ephemeral lives, vanishing into thin air once they have been pronounced.

Contrary to established doctrine, we maintain that uttered sentences are in principle occasion sentences and have no need at all to be dressed up as eternal sentences. Eternal sentences, such as those presented in (7) above, are borderline cases, whose contextual restrictions happen to be zero. ${ }^{9}$ We moreover maintain that the logic of language is intrinsically intensional, and that extensional logic is a borderline case of intensional logic. This will be illustrated in the following two subsections.

\subsection{Anchoring and keying}

To say of a sentence that it is an occasion sentence implies that it is fully interpretable only if used in a proper context. Virtually all sentences are uttered in some given context and are, in fact, made up in such a way that they are only usable in some discourse domains and not in others. ${ }^{10}$ We say that an occasion sentence must be properly anchored in ongoing discourse for it to be interpretable. To account for proper anchoring a mental Discourse Representation or Discourse Domain (DD) is required, containing the information accumulated in preceding discourse in a regimented format. A DD is best seen as a middle term kind of memory (between long term and short term memory), probably specifically designed for the processing of linguistic information, to which each new incoming linguistic message is added (incremented), giving rise to an updated DD. The precise format of a DD is still largely to be specified. Yet it seems certain that new discourse entities ('addresses') are introduced by means of an existential quantifier, and that these addresses serve as anchoring points for definite descriptions in later sentences. Reference to entities in the world is mediated by the addresses. Each address stores whatever properties have been assigned to the intended world referent during the discourse. Other provisions must be made, especially with regard to intensional phenomena. A DD must, for example, open a new intensional subdomain for whatever John is said to believe in sentence (5) quoted above. And many more mechanisms must be postulated, which cannot be elaborated here.

The important thing, however, in the present context is the stipulation that a DD is primarily not a set-theoretic but a qualitative construction. A reduction of domains and addresses to sets and/or functions misses the point. Addresses and domains are characterized by properties labelled as lexical predicates, whose mostly qualitative satisfaction conditions are specified in the mental lexicon of each speaker. Their possible set-theoretic properties matter only when the properties at issue are of a set-theoretic nature, as when quantifying operators like all, some or most are used. A square circle will thus have a DD representation different from that of a married bachelor or a living corpse. And 
the statement that all living persons are dead is represented differently from the statement that some things run and do not run at the same time, although, in terms of logic-driven model-theoretic semantics, both have the null set as their intension.

A number of recent developments in formal semantics recognize the importance of the discourse factor in the semantics of natural language. ${ }^{11}$ This is, of course, an important step in the direction of an adequate recognition of the role of cognition in language. Yet the notions developed and the definitions given are all set-theoretic in nature and not qualitative. The part played by the tools of set theory is disproportionate in relation to the importance assigned to cognitively recognized qualities. To give just one, more or less arbitrary, example, Landman (1986:3) defines a fact or situation as 'a partial function mapping $n+1$-tuples consisting of a (primitive) relation and $n$ objects onto truth values.' This may or may not be correct from a set-theoretic point of view, but it misses the point entirely and does not contribute to an adequate insight into the nature of facts and their role in language and cognition.

Since the matter is of great complexity, and since theoretical progress in this respect has not so far been very satisfactory, we can only give a global indication of the conditions to be fulfilled for a sentence to be properly anchored in a DD. Let us say, by way of indication, that if a sentence $S$ is properly anchored, then at least the following conditions have been fulfilled:

(a) All definite descriptions and nominal deictic expressions have an address in the DD at hand.

(b) Speech act qualities correspond to special (sub)domains.

(c) Tenses are mapped onto a tense representation model.

(d) Intensional expressions are incremented in intensional subdomains, themselves provided with satisfaction conditions.

In principle, an unanchored sentence is uninterpretable, although it does have a meaning. The meaning of an (unambiguous) unanchored, isolated, sentence-type $S$ is now seen as a specification in general terms of the effect $S$ will have when added to any given DD to which $S$ can be anchored, or, in other words, the meaning of a sentence $S$ is the update potential of $S$ in any suitable $D D$. This was, in essence, the formulation used in Seuren (1975:237), but it has been translated by the progressive semanticists who work with discourse representation models in one form or another into the set-theoretic terms of a function, so that now the meaning of a sentence $S$ is a function from $D D s$ to updated DDs. Again, this formulation is no doubt correct, but it misses the point. The point is that the meaning of a sentence $S$ is a manual or specification ensuring that when the sentence is used as a token utterance the property expressed in the main predicate is assigned to the appropriate addresses in the domain at hand. It is the mechanics of that process, the contents of the manual, 
so to speak, that is the primary interest of the semanticist. To have a notion of the corresponding mathematical aspects will certainly be useful at certain points of the enquiry, but it is not the primary purpose.

The overall idea will be clear: discourse domains are postulated as a cognitive intermediary station between uttered sentences and what they are about in the world. In fig. 3 above, the discourse domain is represented as a succession of connected thoughts, each containing a proposition that will have a truth value with regard to the state of affairs in the world to which it is intentionally related. In principle, a DD that is about the world has the truth value of the conjunction of all propositions represented in the main domain of speaker's commitment.

This leads on to the second notion to be discussed in this connection, the notion of keying. We have established that uttered token sentences need anchoring in a DD to be interpretable, but we have not said anything about their relation to the situations in the world and the things occurring in those situations that they are about. We assume that the relation of a sentence $S$ to the world situation it is about is mediated by the DD into which $S$ has been anchored. A DD may be, and normally is, intentionally related to a particular section of the world, the verification domain. This relation is called the key, in deference to the literary notion of a roman à clef. Traditional literature is well-anchored, or else it would not be intelligible, but it normally lacks a key, except when it is about things in the world, as in the case of a roman à clef.

How exactly speaker/writer on the one hand and listener/reader on the other settle upon a particular verification domain is a largely unexplored question. Deictic elements, proper names and the use of tenses are no doubt of crucial importance, but no general account has so far been made available. In any case, it is only in the intentional relationship of the proposition expressed with regard to the verification domain that definite terms acquire a reference object and a proposition acquires a truth value. The imputed direct 'truth' relation between linguistic utterances and the world, represented by the dotted horizontal line in Ogden \& Richards's semiotic triangle (fig. 1) and made explicit in standard model-theoretic semantics, has no place in a causal theory of human linguistic comprehension.

\subsection{Some consequences for ontology}

Any discussion of ontological matters should be prefaced with an essential note of caution. Despite our deeply rooted conviction that we deal with real things when we deal with the world and that truth is one and indivisible, it must be recognized that neither true reality nor real truth can be proved. Ever since Descartes and Kant, competent philosophers have known that the 'thing in itself' (das Ding an sich) is neither provable nor knowable. What every individual knows with undeniable certainty is that he or she has thoughts and emo- 
tions and receives sense data, and, therefore, must exist (Descartes' cogitoprinciple). The rest is conjecture and interpretation. Yet the conjecture and interpretation are not arbitrary or open to subjectivist fudging. On the contrary, Leibniz has taught us, in his coherence theory of truth, that our notions of truth and reality embody the most consistent and most reliable form of conjecture and interpretation available, given the sense data we receive. It seems, in fact, that humans and other animals have been programmed to deal with sense data in a way that secures maximal safety and makes for the most reliable predictions, given the mental capacities that each species is endowed with. In other words, our common version of reality, supplemented with its extension in science, maximizes, within the limits of our mental powers, our chances of survival, which is no doubt why we accept it as reliable and good enough to live by. What that reality, 'out there', really is like, irrespective of our powers of perception and cognition, is a question that will forever remain unanswered, though physical theories about the basic structure of matter perhaps provide a glimpse of what might be expected.

That having been said, we conclude that ontological theories cannot make claims about what actually is 'out there', but only about the optimal assumptions about, or the best construction of, what it is 'out there' that causes our perceptions. In other words, ontology, despite its name, does not give us the world, but merely the best construction of it. When we appear to be making claims about what is and what is not, or about what exists and what doesn't, we are really making claims about the best way of constructing what is or is not, or about what exists or doesn't. It is the task of ontology to provide a construction of the world that optimizes correct predictions in the most consistent and simple possible way. Ontology, in other words, would be just a scientific hypothesis or theory of the basic and most general features of the world, were it not that the terms for non-circular realist checking are lacking.

Given this enormous proviso, we say that we will have to include in our ontology the intensional forms of being so abhorred and despised during the whole of the 20th century, from the Russell of 1905 via Quine till the present day. This we do because, as we have known since Descartes, the one thing we know for certain about the world is that thinking takes place. And an adequate account of thinking requires the assumption of intensional forms of being. Thinking is, by definition, the creation of intensional being.

We follow the Russell of 1903, who, in the passage quoted above from his Principles of Mathematics (1903[37]:449), still distinguished between being and existence, though we will be a little more careful in describing what existence entails. Whereas for Russell 'to exist is to have a specific relation to existence - a relation, by the way, which existence itself does not have' (1903[37]:449), we prefer to say that humans assign existence to those con- 
structed entities that are, in our construction of the world, reckoned to take part in physical chains of cause and effect.

A distinction is thus made between entities that exist and those that have being but do not exist. We accept that human cognition assigns a form of virtual being to thought-up entities, which are in some sense 'projected' into the world. Such virtual entities are defined merely by the properties that have been assigned to them in mental propositional acts.

We enter here upon Meinongian territory. According to Linsky (1967:1116), Meinong reserved subsisting (subsistieren) for 'objectives', roughly, reifications and facts, whereas being (bestehen) was used for the ontological status of virtual objects (entities), and existing (existieren) for that of really existing entities. We shall refrain from an attempt at exegesis of Meinong's texts, which are often very hard to follow, and will follow Linsky's digest. Having first traced Meinong's intellectual roots to Brentano's psychology (1967:12), Linsky then says:

... it is certain that Brentano and his followers understood 'intentionality' in such a way that intentional acts, i.e., mental acts, unlike physical acts, can have non-existent objects. I can think of Santa Claus, though I cannot shake his hand. It is characteristic of mental acts that they are 'directed' to objects, but these objects need not exist. Meinong, as a follower of Brentano, certainly accepted this. He refined and deepened Brentano's analysis. In his theory of objects Meinong distinguished between existence and subsistence, and he protested against our 'prejudice in favor of the actual'.... Referring, unlike hanging, can have a non-existent object. But this is not the same as referring to nothing. (Linsky 1967:17-18)

Virtual or intensional entities are incompletely defined, since, being creatures of imagination, they only have the properties assigned to them in the intensional thought domain that was their birth place. We do not know, for example, whether Sherlock Holmes celebrated his twentieth birthday on his own or with friends or not at all, but as soon as the Sherlock Holmes story cycle is enriched with a story in which his twentieth birthday is described, that particular detail will be filled in. It is possible, of course, for there to be two different stories about that birthday. In that case, Holmes has two incompatible properties, depending on the thought domain one works with. He may even have incompatible properties within the same domain. As long as he does not have to bear the weight of real existence, he can continue his virtual being even with incompatible properties adhering to him.

It must be emphasized that talk about Sherlock Holmes is not talk about the mental representation of Sherlock Holmes. The talk is about the man, even if he is not a really existing man. We analyse an expression like the king, when used as a referring argument term to a predicate, as 'the entity $x$ such that $x$ has been assigned the property of being a king'. Clearly, this assignment may be false, but as long as it helps to identify the entity in question for the purpose of 
predication (the mental assignment of a property), no harm is done. Thus, the example (Donnellan 1966:103-104) of the man drinking a martini, which turns out to refer to a man drinking a glass of water, is not a problem as long as the definite description is merely used referentially, i.e. to single out an entity for the purpose of predication. And a sentence like:

(10) The present king of France is not a king.

may be judged true, since the entity that has been assigned the property of being the present king of France does not exist and thus is an intensional entity, and intensional entities cannot be kings, since to be a king one first has to exist.

In the same manner we shall have to distinguish between extensional and intensional sets of entities. More precisely, whereas in extensional systems I is taken to be the set of all really existing entities in the universe of discourse, we redefine $I$ as the total set of all real and/or virtual entities in the universe of discourse. Then, whereas the notation $[[\mathrm{F}]]$ (or $[[\mathrm{F}(\mathrm{x})]]$, with the variable $x$ added to indicate the empty syntactic place) is standardly used to denote the set of really existing entities $x$ that satisfy the predicate $F$ (the standard extension of $F$ ), we redefine $[[\mathrm{F}(\mathrm{x})]]$ as the set of all real and/or virtual entities $x$ that satisfy the predicate $F(x)$. That is, if $F(x)$ is an intensional predicate yielding truth for intensional entities as well, such as the predicate be worshipped, $[[F(x)]]$ contains all entities, real and/or virtual, that satisfy $F(x)$, or all entities that are worshipped, no matter whether they exist or are merely virtual. Let us call this the revised standard extension of $[[\mathrm{F}(\mathrm{x})]]$.

Moreover, we need the notion intensional extension of $\mathrm{F}$, written $\{\mathrm{F}\}$, or $\{\mathrm{F}(\mathrm{x})\}$, standing for the set of all real and/or virtual entities $x$ that have had the property denoted by the predicate $F$ assigned to them, no matter whether $x$ actually satisfies $F(x)$ and no matter whether $F(x)$ is a purely extensional or an intensional predicate. In 6.3.2 below we will put these notions to good use.

Lastly, we must distinguish between real and intensional facts. In modern philosophy the notion of fact has caused great problems, which can hardly be fully discussed in the present context. We cut this Gordian knot by saying, simply, that a real fact is whatever it is in the world that makes a true proposition true. Real facts, in other words, are truth-makers for propositions. Since facts are inextricably bound up with propositions, we do not speak of 'facts' per se, but only of 'the fact that $p$ ', where $p$ is some proposition. We speak of 'the fact that $p$ ' after the proposition $p$ has been assigned the value 'true' on the strength of the best of our constructive and/or inductive cognitive powers.

Since a fact is the world counterpart of a true proposition, one is tempted to regard the corresponding fact as the extension of the proposition it makes true, but then it must be understood that, unlike normal extensions, a fact does not exist in the world as a fact without the proposition it makes true. A (real) fact 
may be seen as a situational datum which is there in the world but whose ontological form is created by the mental act of putting together a proposition.

From this perspective, facts are reifications, that is, bits of the world not taken to exist in their own right but taken together by a mental construction or formula, like the military-industrial complex or the average age of university professors in Britain, or the difference between John and Harry. Reifications are intensional entities of a special kind. Not thought-up entities that may exist or could exist if the world were different, but thought-up entities whose counterpart in the real world is to be located with the help of a formula of interpretation. ${ }^{12}$ This, clearly, allows for a distinction between extensional and intensional reifications. Extensional reifications are thought-up entities reducible by a formula of interpretation to really existing entities in the real world. Intensional reifications are thought-up entities reducible by a formula of interpretation to intensional entities in some thought-up world. ${ }^{13}$

We now say that real facts are extensional reifications, while intensional facts are intensional reifications. In contrast to real facts, we call an intensional fact whatever it will or would be in the real world that will or would make a proposition true. We speak of intensional facts as long as we are uncertain about the truth value of the corresponding proposition, or after its falsity has been established (in which case we can speak of 'the fact that not- $p$ '). The distinction between real and intensional facts is obvious: real facts are part of the actual, real world, whereas intensional facts may or may not be; they are the product of human imagination in whatever form. One might think of extending the notion of existence to facts and say that real facts have existence and intensional facts have being and perhaps also existence. But such use of these terms is not advisable (and Meinong agreed, if I have understood him correctly), as we think of existing entities as enduring independently of human thought, whereas facts 'exist' only in virtue of human thought: no thoughts, no facts. But we can say that intensional facts are to real facts what intensional entities are to real entities. (Much of science is concerned with finding out whether the intensional facts of scientific hypotheses can be said to be real facts, under some formula of interpretation or construction.)

Meanwhile, we observe that any theory of discourse semantics will have to make adequate provisions for addresses that represent facts and other reifications. So far, no such theory has fulfilled that requirement.

\subsection{Some consequences for logic}

Even though we realize that we are still far removed from a full formalization of the notions that have been presented, we can make a few statements with regard to the logical system taken to underlie cognition and language, without pretending to provide a complete, systematic account of 'the logic of human cognition'. 
Existing logical systems are insufficient for natural language, which allows for reference to individuals who can imagine things and work with an ontology that includes all sorts of imagined scenery and is, therefore, infinitely richer than the 'desert landscape' so beloved of Quine and his associates. If a logic is to account for meaning in natural language it has to be intrinsically intensional, not the product of a programme of extensionalization of intensions, but, conversely, of a programme of intensionalization of extensions. Every utterance stands under the intensional operator of the speaker's thought.

\subsubsection{Presuppositions}

First we note that if a sentence can only have a truth value if it has first been properly anchored in a discourse domain, then the anchoring conditions, i.e. the presuppositions, of a sentence must be part of its truth conditions. If a sentence $S$ is not properly anchored, it is uninterpretable and has no truth value, as in the case of sentence (6) above. If $S$ is properly anchored, but one or more of the elements in the discourse domain that make it so are false, then $S$ is intelligible but false, as when I say:

(11) Nancy's husband is having an affair.

in a situation where there is a Nancy and it has been falsely suggested that she is married. Now (11) is properly anchored, because the DD at hand contains an address for Nancy's husband but the addition of that address to the DD led to falsity. And, of course, if the increment itself brought about by $S$ leads to falsity, $S$ is again false, as when I utter (11) in a situation where Nancy is married, but her husband is not having an affair.

It appears to make good logical and semantic sense to distinguish between these two kinds of falsity: if $S$ is false on account of one or more of its presuppositions being false, we say that $S$ is radically false. If $S$ is false on account of its own increment leading to falsity in the DD, we say that $S$ is minimally false. ${ }^{14}$ The main reason why this distinction makes sense is because the normal, unmarked, negation in natural language appears to leave radical falsity unaffected and to turn minimal falsity into truth and vice versa.

It is a remarkable fact that, despite one or two attempts at accounting for presuppositions in natural language in terms of model-theoretic semantics (e.g. Lewis 1979), very little attention has been paid to them in the formal semantic literature and no satisfactory account has ever been presented there. The subject of presuppositions has been conspicuous for its absence in that literature. We now see that there is a good reason for that: any satisfactory theory of presuppositions in natural language will have to bring in the cognitive aspect of semantic processing, which is something that model-theoretic semantics is not equipped to do. 


\subsubsection{Intensional quantification}

A second obvious point, in this connection, is quantification. Whereas both Aristotelian and Russellian predicate calculus only allow for quantification over really existing entities, we now need to include intensional entities as well.

To see what is at issue, it is easiest to consider a quantifier as a predicate expressing a relation between two sets (i.e. the theory of generalized quantifiers). Restricting ourselves to the two quantifiers that play a dominant role in logic, we say that the universal quantifier (all or $\forall$ ) expresses an inclusion relation of one set in another, whereas the existential quantifier (some or $\exists$ ) expresses the fact that the two sets have a non-empty intersection. Thus, the sentences (12a) and (13a) are analysed logically as (12b) and (13b), respectively, expressed in the language of predicate calculus as (12c) and (13c), respectively:

(12)a. All flags are green.

b. 'the set of flags is included in the set of green things'

c. $\forall \mathrm{x}[\mathrm{G}(\mathrm{x}), \mathrm{F}(\mathrm{x})]^{15}$

(13) a. Some flags are green.

b. 'the set of flags and the set of green things intersect non-emptily'

c. $\exists x[G(x), F(x)]$

The predicate $\forall \mathbf{x}$ (the symbol $x$ is added to avoid confusion when more than one quantifier is involved in the same sentence) is a binary higher order predicate (i.e. it expresses a relation between two sets, not between two individual entities), and it says that the second set, called the restrictor set and here symbolized as ' $\mathrm{F}(\mathrm{x})$ ' (i.e. the set of all things that have the property of being $F$ ), is included in the first set, called the matrix set, here symbolized as ' $\mathrm{G}(\mathrm{x})$ ' (i.e. the set of all things that have the property of being $G$ ). Likewise, the predicate $\exists \mathrm{x}$ is a binary higher order predicate saying that the restrictor set and the matrix set have at least one member in common.

The problem with traditional Aristotelian predicate calculus was that when the restrictor set is empty (read: consists only of intensional entities), the whole system collapses. Modern, Russellian, predicate calculus solved that problem with the help of standard set theory: when the restrictor set is empty, it is by definition included in the matrix set, since the null set is a subset of all sets. Hence, in such cases a universally quantified sentence like:

(14) All mermaids have a bank account.

(where the (empty) restrictor set consists of all mermaids and the matrix set of all entities that have a bank account) is simply true. Likewise, sentence (15) will then be considered true:

(15) All mermaids do not have a bank account. 
Here the restrictor set is, as with (14), the (empty) set of all mermaids, but the matrix set consists of all entities that do not have a bank account. Since the empty set is a subset of all sets, both (14) and (15) are considered true in the terms of Russellian predicate calculus.

This, however, counterintuitive as it already is, leads to further counterintuitive results when applied to intensional predicates like be imaginary, because now the two sentences (16a) and (16b) should both be true, whereas we, normal speakers, clearly feel that (16a) is true and (16b) false:

(16) a. All mermaids are imaginary.

b. All mermaids are not imaginary.

It does seem, therefore, that if justice is to be done to natural language, a provision will have to be made for quantification over intensional entities. In such a theory, the quantifiers cannot simply be treated as binary higher order predicates over sets of really existing entities. The restrictor set will have to be the intensional extension of the predicate $\mathrm{F}(\mathrm{x})$, i.e. $\{\mathrm{F}(\mathrm{x})\}$, as defined above, whereas the matrix set can be the revised standard extension of the predicate $\mathrm{G}(\mathrm{x})$, i.e. [[G(x)]], (re)defined in 6.2 above as the set of all entities, real or virtual, that actually satisfy the predicate $G(x)$, no matter whether $G(x)$ is an extensional predicate or an intensional one (such as be worshipped).

Considering a sentence like:

(17) All unicorns are worshipped.

we now say that (17) is true just in case $\{$ Unicorn(x)\}, or the set of all real and/ or virtual unicorns, is included in the set [[Be worshipped(x)]], or the set of all real and/or virtual entities that are worshipped (since be worshipped is an intensional predicate). Clearly, (17) will be false in case there are any unicorns (virtual ones, to be sure) that are not worshipped. In standard extensional predicate calculus, (17) must be considered true simply because there are no unicorns. It will require little persuasion that a treatment such as proposed here is a great deal subtler and does much greater justice to natural language. ${ }^{16}$

Moreover, in view of what has been said in 6.3.1 above, an adequate theory of quantification in natural language will have to take into account presuppositional phenomena as well and will have to work with a negation that inverts truth and minimal falsity but leaves radical falsity unaffected. For a formally precise attempt at such a theory, see Seuren (in preparation).

\section{The cognitive deficiency in linguistics}

Having reviewed the cognitive deficiencies of the standard forms of modeltheoretic semantics, we now turn to what is considered to be linguistics in a stricter sense, the study of linguistic forms and constructions. Linguistics was 
no exception to the general drive among the human sciences forscientific status that started in the 19th and prevailed throughout the 20th century. Around the year 1900, this meant that the human sciences strove to live up to the standards set by the then fashionable positivistic notion of science: science was seen mainly as an extensive, systematic gathering of verifiable facts, involving only really existing, preferably material, entities. Scientific statements regarding facts should be fully verifiable, which meant among other things that any abstract or general notions should be fully reducible to material individual entities and theories were regarded with suspicion. A few decades later, when neopositivism had succeeded positivism, these requirements were somewhat relaxed and greater emphasis was placed on predictive theories and on scientific explanation. After roughly 1960 , as a joint result of developments in the philosophy of science and of the emergence of computers, the human sciences went through the so-called cognitive revolution, which meant that mind and meaning became fashionable topics again, as it proved possible and fruitful to talk about the mind in operational terms drawn from computer science. This, of course, was very promising with regard to the cognitive dimension in the study of language. But how much of that promise actually came to fruition?

It is fair to say that, on the whole, linguistics has always simply followed the general trends in the philosophy and methodology of science, occasionally actively contributing, but mostly in a purely passive role. During the late 19th century, when linguistics was still equivalent with comparative philology, i.e. the historical reconstruction of the Indo-European languages and their genetic relationships, the psychological aspects of language already began to be looked at with suspicion. Comparative philology constituted a scientific feat of the highest rank, supported by formally precise analyses and descriptions. But the human mind as a factor underlying the structure and use of language was hardly at issue. In fact, as we understand from the Young Grammarian Delbrück's exchange with Wundt in 1901 (Delbrück 1901; Wundt 1901), there was a distinct wish among the comparative philologists of those days to stay away from any form of psychological theorizing and stick to purely linguistic analyses. When, soon after this, the non-historical study of language came off the ground and became the kind of linguistics we have grown up with, this aversion to psychology was inherited. Both De Saussure and Bloomfield insisted on the 'autonomy' of linguistics, wishing to shield linguistics not only from psychology, but also from logic and philosophy, and even, by that time, from comparative philology (see Seuren 1998:192-193).

This went well for a time. European structuralism never did much to explore the relation between language on the one hand and mind and meaning on the other. It simply failed to fill the gap between, on the one hand, observable linguistic form and, on the other, the cognitive and semantic factors at work in 
language and language use. The psychology appealed to in European linguistics was mainly folk psychology.

The psychologist-philosopher Karl Bühler, with his book Sprachtheorie of 1934, was an exception. His primary concern was to explain linguistic structures in terms of the psychological processes of thought and perception involved in the use of language, taking into account not only contemporary Gestalt psychology (which emphasized the fact that a composite object is primarily perceived as an organized whole, a 'Gestalt'), but also a wide range of philosophical positions. His work, however, had virtually no impact on either European or American linguistics.

Another important exception was the work done in the Prague School with respect to Vilém Mathesius's (1928) notion of Functional Sentence Perspective, which implied a distinction between, on the one hand, given or old information in an uttered sentence, located in the theme or topic, and, on the other, a rheme or comment expressing the new information presented. Although this notion suffered for a number of decades from a lack of formal precision, modern studies in the field of information structure (in combination with intonation studies) are giving it more precision and substance. A link-up with discourse semantics, as sketched in section 6 above, would seem natural and potentially very fruitful.

In phonology, which dominated language studies for a while from 1930 on, meaning was treated as a phenomenon that was simply there and could be used, to some extent, to differentiate the functional sound units called phonemes. But this use of meaning never led to a more basic investigation into the nature of meaning.

From an overall point of view one may say that, as the 20th century proceeded, mind and meaning were either forgotten or taken for granted in European linguistics. In fact, it was considered suspect or even unprofessional, around the middle of the 20th century, to engage in what was seen as speculations about such intangible things as 'mind' or 'meaning'. Appeals to either psychology or logic were condemned, as language was considered to be an autonomous system, capable of standing on its own legs. At the time, this was less gross than it may sound now, as European linguistics was still reeling from the frustrating discussions around logical, psychological and grammatical notions of subject and predicate, discussions that had lasted for about eighty years and had dominated whatever little theoretical talk there was about language. ${ }^{17}$ Around 1930 these discussions ended in notional and terminological confusion (Seuren 1998:120-133). In general, Europe suffered, in its own way, from an antimentalistic complex that was more emotional than rational.

In America, things were, though similar, not quite the same. The main difference was the rise of behaviourism, first limited to psychology proper, then 
spreading to the human sciences in general. American structuralist linguistics was mainly oriented towards behaviourism, on which it relied to provide the necessary conceptual grounding. The dominant tendency was to explain meaning in terms of conditioned responses, while the mind was either reasoned away or reduced to a trivial mechanism of dispositions conditioned by stimulus association. One only has to think of chapter 2 in Bloomfield (1933) or of Skinner's Verbal Behavior (1957). But these attempts to get rid of the really hard questions relating to language and use of language were soon seen to be irredeemably inadequate, with the result that they rapidly disappeared from the agenda with the advent of the cognitive revolution.

Meanwhile, American structuralist linguistics was predominantly antimentalistic and antisemantic, culminating in Z. Harris's early work (1951), which proclaimed the ideal of a theory of language, without any appeal to meaning. In a sense, this development was extremely fruitful. The exclusive focusing on linguistic form made linguists see that grammatical constructions are subject to an intricate system of restrictions or 'rules', which together define the identity of a language. Linguists like Zellig Harris and Charles Hockett, moreover, made a connection with newly developed branches of mathematics, in particular the theory of algorithms, which provided a deeper and more general insight into the properties of rule systems, or grammars, which define the structural possibilities of strings of symbols in a language. It was thus that the theory of generative grammar developed in the school of Zellig Harris during the late 1940s and early 1950s.

In the early days of generative grammar, a grammar was seen as an algorithmic random generator of sentences, meant to be able to produce any one of the infinite set of wellformed sentences of the language at issue, regardless of their (finite) length, and unable to produce any illformed string of morphemes. ${ }^{18}$ Within a few years, however, this abstract, formal theory of grammars was assigned a realist interpretation: during the early 1960s an algorithmic generative grammar came to be seen as a model of the native speaker's linguistic competence, that is, his ability to use wellformed and to avoid illformed sentences. Understandably, it did not take long for it to be realized that, obviously, a native speaker's competence involves more than just the ability to produce wellformed and to avoid illformed sentences. It was proposed (Katz \& Fodor 1963; Katz \& Postal 1964) that a so-called 'semantic component' should be added to the generative grammatical model that was current in those days. This semantic component should, in principle, 'project' syntactic structures onto a semantic representation, thus accounting for the fact that sentences have a meaning and that competent speakers are not only able to produce syntactically wellformed sentences but also know what they mean.

It is fairly obvious that the call for a 'semantic component' during the early 1960 s was a consequence of the cognitive revolution in psychology and adjacent 
human sciences. In fact, virtually all theories of grammar that have seen the light since 1960 one way or another take meaning into account.

The Chomskyan tradition, which went from the so-called 'Extended Standard Theory' of 1970 to the Minimalist Programme of 1995, adopted the notion of 'logical form', thereby paying its tribute to semantics without, however, doing anything about it. ${ }^{19}$ By contrast, the Generative Semantics movement, which came about during the late 1960s but was nipped in the bud during the 1970s, contained the promise of bringing the study of grammar a great deal closer to the ideal of psychological plausibility and of accounting for the semantic aspects of language in a truly cognitive fashion. In fact, it conquered the world even more quickly than the random generator model had done a decade earlier. But although its research programme was clear and the chances of success were realistic, as was appreciated by vast numbers of linguists all over the world, it was never given a fair chance, due to sociological factors within the community of linguists that had little to do with academic merit or argument. ${ }^{20}$

As it is, the Chomskyan tradition in generative grammar has lagged behind most other theories of grammar in that its interest in semantics and cognition has amounted to little more than lip service. The fact that this tradition still clings to a random generator view of grammar shows the lack of realism of its claims to a realist cognitive interpretation. In general, this approach is characterized by a disquieting contrast between, on the one hand, its ambitious theoretical goals and, on the other, its shaky empirical support (despite frequent claims or suggestions in Chomsky 1995 of empirical results already achieved or still under way in 'promising work', without them ever being identified) ${ }^{21}$

Other theories take semantics more seriously. Categorial Grammar constitutes the most forceful and systematic attempt at maintaining direct surface structure semantics, without the intervention of a separate level of semantic representation. Generalized Phrase Structure Grammar (GPSG) (Gazdar et al. 1985), and its successor Head-Driven Phrase Structure Grammar (HPSG) (Pollard \& Sag 1994), Tree Adjoining Grammars (TAG) (Joshi 1987), and many other theories, each define the relation of surface structure to semantic interpretation in their own way, which it would take too long to discuss in the present context. Implicitly or explicitly, most present-day grammatical theories consider a grammar to be a mediator between sound and meaning. This in itself is undoubtedly an important step forward. Yet the semantics used in these theories is predominantly of the Montagovian model-theoretic kind which, as we have seen above, is empirically not viable due to its cognitive inadequacies. These theories have no window on the cognitive world of thought, which rather limits their relevance for a proper insight into the nature of language.

The only modern theory of grammar that makes a direct and explicit appeal to cognition is Cognitive Grammar (e.g. Langacker 1987, 1991), for which rea- 
son this development merits special attention in the present context. This theory is primarily motivated by considerations of psychological plausibility and aims at a full reduction of human language to the general principles of human cognition. In so far as this initiative manifests a desire to integrate the study of language into the study of cognition, it is certainly to be applauded, as there is no denying that human language is indeed primarily a cognitive phenomenon. And some positive results have certainly been achieved. Any fair observer will have to agree that the Cognitive Grammar approach has booked considerable successes in the field of lexical semantics, where full recognition is granted to such essential factors as viewpoint, functionality, prototypicality and the like, thus showing the basic inadequacy of extensionalist approaches to lexical meaning. It is no coincidence that formal semantics has conspicuously failed in the field of lexical semantics.

As regards grammar, however, Cognitive Grammar appears to overshoot its purpose in assuming that the principles of grammar are just instances of general cognitive principles. While this might seem a priori plausible and methodologically preferable (as an application of Ockham's razor), present-day knowledge of grammatical structures and processes does not support such a view. Linguists have learned, over the past half century, that the nature of the grammatical data that are available today is such that a formally precise system of grammar is required as their explanatory source. Despite the vast differences of opinion among the various schools regarding the principles and rules that are taken to make up the grammar systems of the world's languages, there appears to be an overall agreement that those principles and rules are only remotely related to, or governed by, general principles of cognition, if at all. Where grammatical analyses have been most successful, across the different schools, no similarity with any known general cognitive principle can be pointed out.

A few examples may illustrate this. Consider the phenomenon of Auxattraction (or Subject-Aux inversion) as a corollary of constituent preposing in the Germanic languages. In English, this phenomenon is restricted to the preposing of non-subject WH-question constituents (including the zero instance occurring with yes/no questions), and of negative and seminegative constituents. In German and Dutch Aux-attraction occurs with any non-subject constituent preposing (including overt and covert WH-constituents). Some interesting and valuable cognitivist literature (e.g. Kuteva 2001) has been published recently on the subject of auxiliation, providing support for the view that auxiliation as a historical process (cp. M. Harris \& Ramat 1987) is cognitively functional. Yet the strictly grammatical question of how exactly auxiliation is implemented in the grammatical systems of the languages concerned is not, or only sketchily, answered. This question is answered by formal grammarians, who have come up with a variety of analyses. These 
analyses, however, show no possible link with general cognitive principles and more often than not they impress one as being communicatively dysfunctional (to the extent that communicative functionality can be gauged).

Another example is provided by phenomena of verbal clustering in numerous languages. ${ }^{22}$ V-clustering is manifest, for example, in German and Dutch, which have clauses like (18a) or (18b), both meaning 'because I could have let the man deliver the book to me' (the V-clusters are indicated):

(18) a. ... weil ich den Mann mir das Buch v[hätte besorgen lassen können] b. ... omdat ik de man mij het boek v[had kunnen laten bezorgen]

It is fairly obvious that such a construction, where all NPs of different ranks are aligned on the left and all verbs of different ranks are clustered on the right (with occasional leaps in ordering directionality), can hardly be considered communicatively functional or cognitively motivated. Yet that is how some languages encode the underlying meaning. It does not seem that Cognitive Grammar has much to say here, which invites the conclusion that formal grammar remains necessary, next to a broader investigation of the links that exist between language and 'open' cognition.

The large number of cases of descriptive success on the basis of 'autonomous' grammatical rules and principles has convinced most theoretical grammarians that, barring lexical selection, the processes that convert semantic structures (thoughts) into sound and vice versa are cognitively encapsulated (as indicated in fig. 3 above). This means that they are automatic routines, screened off from introspection or awareness and not open to conscious interference by the speaker (see for example ch. 2 in Seuren 2001). They are, in other words, in some sense modular (though the physical correlate of this form of modularity is still unknown).

The assumption of modularity for the grammatical machinery mapping semantic structures onto sounds and vice versa does not contradict the insistence on the cognitive dimension. On the contrary: encapsulated modular routines are well-known in the study of cognition. In fact, for good functional reasons, most of the ancillary work done in or by cognition takes place 'underground', way beyond any conscious access. Had this not been so, even a small cognitive effort would risk to blow up the system, as the processes that are open to awareness are extremely costly in terms of brain space, operating time and memory. No functional purpose is served by making ancillary tasks open to conscious inspection.

If grammar is seen as an ancillary mechanism (and there appears to be no reason why it should not be so considered), it makes sense to accept the view that grammar is a purpose-built routine procedure, separate from the principles and procedures that guide the mental operations that are more open to aware- 
ness. In rejecting this view, Cognitive Grammar pays the price of insufficient formal precision. Its explanatory principles as well as its predictions are too often intuitive and not open to precise testing (difficult enough as that is in linguistics). It excels in pointing out often subtle semantic differences (the semantics being open to control and awareness), but fails systematically to show the general cognitive relevance of assigning specific syntactic or morphological status to morphemes or constructions, as indeed it is badly lacking in specifying the precise properties of syntactic or morphological structures. The result is an antiformalist attitude in grammar and semantics, which has severely limited the relevance of Cognitive Grammar in these areas.

Moreover, Cognitive Grammar fails to tackle the philosophical and methodological issues that have been raised in the present paper. Given the stringency of the arguments and the depth of the issues involved, this cannot be done with impunity. If the cognitive grammarians could be persuaded to take matters of truth and falsity, logic, and philosophical questions of being and existence, to mention just a few, more seriously, they might change their attitude with regard to formal theories and the modularity of grammar, and thus give greater weight and substance to their claims.

Perhaps, the overall conclusion must be that, while most contemporary theories of grammar and meaning appear to be in a phase where often serious and promising attempts are made to integrate the study of language into that of cognition, it is not generally recognized that one has to go back to the very ontological and epistemological foundations of logic and language if a real cognitive revolution in the study of language is to be brought about. A philosophically and formally solid account is needed of the fact that natural language, like natural thinking, is basically intensional. Such a study will then provide the basis for a principled theory of semantic structure, and thus for a principled theory of grammar, the mechanism that maps semantic structures and physical linguistic utterances onto each other.

\section{Notes}

* This paper was presented, in a shortened form, as the Presidential Address at the annual meeting of the Societas Linguistica Europaea at Leuven University on August 28, 2001.

1 Even though fig. 3 shows a more elaborate architecture than fig. 2, it is still far from complete. For example, the double arrow between "LEXICON PLUS GRAMMAR" and "SURFACE STRUCTURE" is, in all likelihood, a gross simplification. Whereas the top-down arrow may be justified in that the generation process, given a well-defined thought structure as input, has many of the characteristics of an insulated algorithmic procedure, the bottom-up process of parsing seems much less straightforward. Since the parsing process appears to be much more dependent on outside inputs from context and general cognition, one may assume that it is less insulated and, in principle, non-compositional. Other elements in fig. 3 suffer from similar defects. In the present context, however, we must refrain from any attempt at rendering such details visible in the schematic architecture. 
2 I am indebted to my student Cor Burger for helping me sort out this particular episode.

3 See, for example, his brazen statement in Russell (1957:389): 'I agree, however, with $\mathrm{Mr}$ Strawson's statement that ordinary language has no exact logic.'

4 One remembers Quine's slogan: 'No entity without identity.' For a substantial critique of this Quinean principle, see Strawson (1997).

5 Russell writes (1905a:485): 'Yet if we enumerated the things that are bald, and then the things that are not bald, we should not find the present king of France in either list. Hegelians, who love a synthesis, will probably conclude that he wears a wig.' The quip is, of course, rhetorically powerful. Yet Meinong would reply (other than Russell's Hegelians) that the non-existent king of France will be found in the list of things that are not bald, since to be really bald one first has to exist. Remarkably also, Russell is happy with the fact that in his predicate calculus All present kings of France are bald and All present kings of France are not bald are true at the same time when there is no king of France, whereas he ridicules the position that The present king of France is bald and The present king of France is not bald could be considered true at the same time in cases where there is no such king. See Linsky (1967) for informed comment.

6 See in particular Montague's extremely influential paper (1973).

7 To say that hope-worlds are a subset of belief-worlds will not do, as shown by, for example:

(i) John doesn't think there is a thief in the attic, but he hopes that if there is one, the man will be unarmed.

8 Both the theory and the practice of automatic translation have shown that meaning cannot be determined compositionally: if it could, there would now be adequate machine translation programs. Any competent translator knows that to translate a text properly one has to have knowledge of what the text is about. This applies not only to technical texts, where the knowledge requirement is usually highly obvious, but also to non-technical texts, where this requirement is often hidden by the triviality of the knowledge required.

9 The same point is made in Barwise \& Perry (1983:5-6) (where the curious terms 'efficient' and 'nonefficient' are used for 'occasion' and 'eternal', respectively). Seuren et al. (2001) gives extensive arguments for the position that occasion sentences are the norm and eternal sentences are mere borderline cases.

10 In Seuren (1985) and elsewhere it is argued extensively that these anchoring conditions are in effect what is usually called the presuppositions of a sentence; this aspect will be taken up again in section 6.3 below.

11 See, for example, Kamp (1981), Barwise \& Perry (1983), Veltman (1985), Landman (1986), Groenendijk \& Stokhof (1991), Kamp \& Reyle (1993).

12 If the formula of interpretation is vague or ill-defined, so is the reification. Vague reifications are common, but a threat to clear thinking.

13 As I understand it, Meinong called the form of being of extensional reifications subsisting. He apparently had no term for the form of being of intensional reifications.

14 For extensive discussion of the logical and semantic technicalities and the corroborating empirical observations, see for example Seuren $(1985,2000)$, Seuren et al. (2001).

15 The notation normally used is: , $\mathrm{x}[\mathrm{F}(\mathrm{x}), \mathrm{G}(\mathrm{x})]$, with the restrictor set first and the matrix set second. For reasons to do with the grammatical processing of predicate calculus formulae I prefer the notation as used in the text.

16 Informed readers will, of course, refer to Montague (1973), where sentences like John talks about a unicorn are analysed in his possible world framework. The answer to this is that in such an analysis the sentences John talks about a square circle and John talks about a married bachelor have identical truth conditions, which is an unacceptable result for the semantics of natural language. Given the basic premisses of possible world semantics, it does seem that this defect cannot be repaired just as the problem signalled 
above in connection with (2) and (3) has so far proved unsolvable in that framework. That being so, one may well feel justified in not wishing to spend the inordinate amount of time and energy needed for a full command of Montague's extremely complex formal systems.

17 But for De Saussure, who had given the example of not mentioning the subject-predicate debate at all.

18 The term random generator was first introduced in Yngve (1962), in a mathematically oriented context to which the critique formulated here does not apply at all. Chomsky rejects the term on the grounds that his 'generative' theory of grammar should not be seen as a competence model, but only as an abstract characterization of the sentences of a language. In light of his purported realism, however, this is disingenuous, since nonalgorithmic 'abstract characterizations' are per se not amenable to a realist interpretation, as their descriptive power is based on logical, not on causal entailments, whereas any realist theory must make an appeal to causal factors. Any realist theory of grammar, therefore, must be interpretable as defining real time generative processes, i.e. as an implementable algorithm. When Chomsky's generative theory of grammar (in any of its appearances) is formulated as an algorithm, as he himself does when he tries to achieve formal precision, it appears immediately that the process of sentence production is totally unrestricted. Factors of intended meaning, order of statistical frequency, or whatevever, play no role at all. It is this notion of 'random generator' that is at issue here.

19 In fact, as was pointed out by Johnson \& Lappin (1997), the 'logical form' invoked in Chomsky (1995) is totally undefined, and, to the extent that one catches a glimpse of what may actually be intended, semantically absurd.

20 For detailed accounts of this strange episode, see R. Harris (1993), Huck \& Goldsmith (1995), Seuren (1998:512-527). Newmeyer (1980) is clearly partisan, as shown in McCawley (1980).

21 It would seem that whatever useful analyses or descriptions have been presented in this framework can profitably be reformulated in terms of more sedate and better founded formalisms.

22 Cp. for example Bech (1983), Starosta (1971), Seuren (1972), Langacker (1973), Evers (1975), Rambow (1994), Hinrichs et al. (1998).

\section{Address of the author:}

Pieter A.M. Seuren

Max Planck Institute for Psycholinguistics

PO Box 310

NL - 6500 AH Nijmegen (The Netherlands)

email: pieter.seuren@mpi.nl

\section{References}

Barwise, Jon and John Perry. 1983. Situations and Attitudes. Cambridge, Mass.: MIT Press. Bech, Gunnar. 1983. Studien über das deutsche Verbum infinitum. Tübingen: Niemeyer. Bloomfield, Leonard. 1933. Language. New York: Holt.

Bühler, Karl. 1934. Sprachtheorie. Die Darstellungsfunktion der Sprache. Jena: Fischer. Chomsky, Noam. 1995. The Minimalist Program. Cambridge, Mass.: MIT Press.

Delbrück, Berthold. 1901. Grundfragen der Sprachforschung. Strasbourg: Trübner.

Donnellan, Keith. 1966. "Reference and Definite Descriptions." Philosophical Review 75, 281304.

Dowty, David R., Robert E. Wall and Stanley Peters. 1981. Introduction to Montague Semantics. Dordrecht: Reidel. 
Evers, Arnold. 1975. The Transformational Cycle in Dutch and German. PhD-thesis, Utrecht University.

Frege, Gottlob. 1918. "Der Gedanke: eine logische Untersuchung." Beiträge zur Philosophie des deutschen Idealismus 1.1, 58-77.

Gazdar, Gerald, Ewan Klein, Geoffrey K. Pullum and Ivan A. Sag. 1985. Generalized Phrase Structure Grammar. Oxford: Blackwell.

Groenendijk, Jeroen A. G. and Martin B. J. Stokhof. 1991. "Dynamic Predicate Logic." Linguistics and Philosophy 14, 39-100.

Harris, Martin and Paolo Ramat (eds.). 1987. Historical Development of Auxiliaries. Berlin: Mouton de Gruyter.

Harris, Randy A. 1993. The Linguistics Wars. New York-Oxford: Oxford University Press.

Harris, Zellig S. 1951. Methods in Structural Linguistics. Chicago: The University of Chicago Press.

Hinrichs, Erhard W., Andreas Kathol and Tsuneko Nakazawa (eds.). 1998. Complex Predicates in Nonderivational Syntax. (=Syntax and Semantics 30). San Diego-London: Academic Press.

Huck, Geoffrey J. and John A. Goldsmith. 1995. Ideology and Linguistic Theory. Noam Chomsky and the Deep Structure Debate. London \& New York: Routledge.

Johnson, David E. and Shalom Lappin. 1997. "A Critique of the Minimalist Program." Linguistics and Philosophy 20, 273-333.

Joshi, Aravind K. 1987. “An Introduction to Tree Adjoining Grammars.” In: Alexis ManasterRamer (ed.), Mathematics of Language. Amsterdam: Benjamins.

Kamp, Hans. 1981. "A Theory of Truth and Semantic Representation." In: Jeroen A. G. Groenendijk, Theo M. V. Janssen, Martin B. J. Stokhof (eds.), Formal Methods in the Study of Language 1. Amsterdam: Mathematisch Centrum, 277-322.

Kamp, Hans, and Uwe Reyle. 1993. From Discourse to Logic. Introduction to Model-Theoretic Semantics of Natural Language, Formal Logic and Discourse Representation Theory. Dordrecht: Kluwer.

Katz, Jerrold J. and Jerry A. Fodor. 1963. "The Structure of a Semantic Theory." Language $39.2,170-210$.

Katz, Jerrold J. and Paul M. Postal. 1964. An Integrated Theory of Linguistic Descriptions. Cambridge, Mass.: MIT Press.

Kuteva, Tania. 2001. Auxiliation. An Enquiry into the Nature of Grammaticalization. Oxford: Oxford University Press.

Landman, Fred. 1986. Towards a Theory of Information. The Status of Partial Objects in Semantics. PhD-thesis, Amsterdam University.

Langacker, Ronald W. 1973. "Predicate Raising: some Uto-Aztecan evidence.” In: B. B. Kachru, R. B. Lees, Y. Malkiel, A. Pietrangeli, S. Saporta (eds.) Papers in Honor of Henry and Renée Kahane. Urbana-Chicago-London: University of Illinois Press, 468-491.

Langacker, Ronald W. 1987. Foundations of Cognitive Grammar. Vol. 1: Theoretical Prerequisites. Stanford CA: Stanford University Press.

Langacker, Ronald W. 1991. Foundations of Cognitive Grammar. Vol. 2: Descriptive Application. Stanford CA: Stanford University Press.

Lewis, David. 1979. "Scorekeeping in a Language Game." In: Reiner Bäuerle, Urs Egli and Arnim von Stechow (eds.), Semantics from Different Points of View. Berlin-HeidelbergNew York: Springer, 172-187.

Linsky, Leonard. 1967. Referring. London: Routledge \& Kegan Paul.

McCawley, James D. 1980. Review of Newmeyer (1980). Linguistics 18.9/10, 911-930.

Mathesius, Vilém. 1928. "On linguistic characterology with illustrations from modern English." In: Actes du Premier Congrès International de Linguistes à La Haye. Reprinted 
in: J. Vachek (ed.), A Prague School Reader in Linguistics. Bloomington, Indiana: Indiana University Press, 1964, 59-67.

Meinong, Alexius (ed.). 1904. Untersuchungen zur Gegenstandstheorie und Psychologie. Leipzig: Barth.

Montague, Richard. 1973. “The Proper Treatment of Quantification in Ordinary English.” In: K. Jaakko, J. Hintikka, Julius M. Moravcsik and Patrick Suppes (eds.), Approaches to Natural Language. Proceedings of the 1970 Stanford Workshop on Grammar and Semantics. Dordrecht: Reidel, 221-242.

Newmeyer, Frederick J. 1980. Linguistic Theory in America. The First Quarter-Century of Transformational Generative Grammar. New York-London-Toronto-Sydney-San Francisco: Academic Press. (2nd revised edition 1986).

Ogden, Charles K. and Ivor A. Richards. 1923. The Meaning of Meaning. A Study of the Influence of Language upon Thought and of the Science of Symbolism. London: Routledge \& Kegan Paul.

Pollard, Carl and Ivan A. Sag. 1994. Head-Driven Phrase Structure Grammar. Chicago: The University of Chicago Press.

Quine, Willard V.O. 1953. From a Logical Point of View. Logico-Philosophical Essays. Cambridge, Mass.: Harvard University Press.

Quine, Willard V.O. 1960. Word and Object. Cambridge, Mass.: MIT Press.

Rambow Owen. 1994. Formal \& Computational Models for Natural Language Syntax. PhDdiss. University of Pennsylvania.

Russell, Bertrand. 1903[37]. The Principles of Mathematics. 1937: Second edition. Allen \& Unwin, London. 1903: Cambridge University Press.

Russell, Bertrand. 1905a. "On denoting." Mind 14, 479-493.

Russell, Bertrand. 1905b. Review of Meinong (1904) in Mind 14, 530-538.

Russell, Bertrand. 1957. "Mr Strawson on referring." Mind 66, 385-389.

Seuren, Pieter A. M. 1972. Predicate Raising and Dative in French and Sundry Languages. Magdalen College, Oxford. (Published as chapter 7 in Seuren 2001).

Seuren, Pieter A. M. 1975. Tussen taal en denken. Een bijdrage tot de empirische funderingen van de semantiek. Utrecht: Oosthoek, Scheltema \& Holkema.

Seuren, Pieter A. M. 1985. Discourse Semantics. Oxford: Blackwell.

Seuren, Pieter A. M. 1998. Western Linguistics. An Historical Introduction. Oxford: Blackwell.

Seuren, Pieter A. M. 2000 "Presupposition, Negation and Trivalence." Journal of Linguistics 36:261-297.

Seuren, Pieter A. M. 2001. A View of Language. Oxford: Oxford University Press.

Seuren, Pieter A. M. (in preparation) "Intensional Quantification."

Seuren, Pieter A. M., Venanzio Capretta and Herman Geuvers. 2001. "The logic and mathematics of occasion sentences." Linguistics and Philosophy 24.5:531-595.

Skinner, Burrhus F. 1957. Verbal Behavior. New York: Appleton-Century-Crofts.

Starosta, Stan. 1971 Lexical variation in a case grammar. Working Papers in Linguistics 3.8. Department of Linguistics, University of Hawaii, Honolulu.

Stout, George F. 1896. Analytical Psychology. 2 vols. London: Sonnenschein / New York: Macmillan.

Strawson, Peter F. 1997. Entity and Identity. Oxford: Oxford University Press.

Veltman, Frank. 1985. Logics for Conditionals. PhD-thesis, Amsterdam University.

Wundt, Wilhelm. 1901. Sprachgeschichte und Sprachpsychologie. Mit Rücksicht auf B. Delbrücks "Grundfragen der Sprachforschung”. Leipzig: Engelmann.

Yngve Victor H. 1962. "Random generation of English sentences." In: Proceedings of the 1961 International Conference on Mechanical Translation and Applied Language Analysis, Teddington, England (National Physical Laboratory Symposium Number 13), London: Her Majesty's Stationery Office, Vol I, 65-80. 